\title{
Parcelamento de doses da adubação nitrogenada na produtividade e qualidade fisiológica de sementes de trigo
}

\author{
Jéssica de Lucena Marinho ${ }^{1}$, José Henrique Bizzarri Bazzo ${ }^{1}$, Carolina Pereira Cardoso ${ }^{2}$, Claudemir Zucareli ${ }^{1}$ \\ ${ }^{1}$ Universidade Estadual de Londrina - UEL, PR. ${ }^{2}$ Universidade Estadual Paulista - UNESP, SP. E-mail: \\ ilmarinho@live.com
}

\begin{abstract}
Resumo
A aplicação de nitrogênio $(\mathrm{N})$ na dose correta e no momento adequado pode favorecer a produtividade e a qualidade das sementes de trigo. Neste sentido, objetivou-se avaliar o efeito do parcelamento e doses da adubação nitrogenada sobre a produtividade e a qualidade fisiológica de sementes de cultivares de trigo. As sementes foram produzidas no Centro Nacional de Pesquisa de Soja, em Londrina-PR, em delineamento experimental de blocos casualizados em esquema fatorial $2 \times 7$, com quatro repetições. Os fatores foram constituídos por duas cultivares (BRS Gralha-azul e BRS Sabiá) e sete combinações de doses e parcelamentos da adubação nitrogenada $\left(0 \mathrm{~kg} \mathrm{ha}^{-1}, 40 \mathrm{~kg} \mathrm{ha}^{-1}\right.$ no perfilhamento, $80 \mathrm{~kg} \mathrm{ha}{ }^{-1}$ no perfilhamento, $40 \mathrm{~kg} \mathrm{ha}^{-1}$ na semeadura, $80 \mathrm{~kg} \mathrm{ha}^{-1}$ na semeadura, $40 \mathrm{~kg} \mathrm{ha}^{-1}$ na semeadura $+40 \mathrm{~kg} \mathrm{ha}{ }^{-1}$ no perfilhamento, $20 \mathrm{~kg} \mathrm{ha}^{-1}$ na semeadura $+60 \mathrm{~kg} \mathrm{ha}^{-1}$ no perfilhamento). Foram avaliados: produtividade, germinação, primeira contagem da germinação, comprimento e massa seca de plântulas, emergência de plântulas em areia e índice de velocidade de emergência. Os dados foram submetidos à análise de variância com comparação de médias pelo teste $\mathrm{F}$, entre os genótipos, e Scott-Knott, entre as combinações de N. $\mathrm{O}$ efeito da fertilização nitrogenada sobre a produtividade de sementes varia com a cultivar. A aplicação de 80 $\mathrm{kg} \mathrm{ha}^{-1} \mathrm{~N}$ na semeadura, favorece o vigor das sementes para a BRS Gralha-azul, e a aplicação de $40 \mathrm{~kg} \mathrm{ha}^{-1} \mathrm{~N}$ na semeadura, ou $80 \mathrm{~kg} \mathrm{ha}^{-1} \mathrm{~N}$ no perfilhamento favorece a produção de sementes de qualidade para a BRS Sabiá. O suprimento inadequado de $\mathrm{N}$ prejudica a qualidade fisiológica das sementes produzidas.

Palavras-chave: Doses de nitrogênio; germinação; macronutriente; vigor; Triticum aestivum L.
\end{abstract}

\section{Splitting of doses of nitrogen fertilization on the productivity and physiological quality of wheat seeds}

\begin{abstract}
The application of nitrogen $(\mathrm{N})$ in the correct dose and at the right time can favor the productivity and quality of wheat seeds. In this sense, the aim was to evaluate the effect of splitting and doses of nitrogen fertilization on the productivity and physiological quality of seeds of wheat cultivars. The seeds were produced at the National Soybean Research Center, in Londrina-PR, in a randomized block experimental design in a $2 \times 7$ factorial scheme, with four replications. The factors were constituted by two cultivars (BRS Gralha-azul and BRS Sabiá) and seven combinations of doses and splitting of nitrogen fertilization ( $0 \mathrm{~kg} \mathrm{ha}^{-1}$, $40 \mathrm{~kg} \mathrm{ha}^{-1}$ at tillering, $80 \mathrm{~kg} \mathrm{ha}^{-1}$ at tillering, $40 \mathrm{~kg} \mathrm{ha}^{-1}$ at sowing, $80 \mathrm{~kg} \mathrm{ha}^{-1}$ at sowing, $40 \mathrm{~kg} \mathrm{ha}^{-1}$ at sowing + $40 \mathrm{~kg} \mathrm{ha}^{-1}$ at tillering, $20 \mathrm{~kg} \mathrm{ha}^{-1}$ at sowing $+60 \mathrm{~kg} \mathrm{ha}^{-1}$ at tillering). The following were evaluated: productivity, germination, first germination count, length and dry mass of seedlings, emergence of seedlings in sand and emergence speed index. The data were subjected to analysis of variance with comparison of means by the $\mathrm{F}$ test, between genotypes, and Scott-Knott, between $\mathrm{N}$ combinations. The effect of nitrogen fertilization on seed productivity varies with the cultivar. The application of $80 \mathrm{~kg} \mathrm{ha}^{-1} \mathrm{~N}$ at sowing favors the vigor of the seeds for BRS Gralha-azul, and the application of $40 \mathrm{~kg} \mathrm{ha}^{-1} \mathrm{~N}$ at sowing, or $80 \mathrm{~kg} \mathrm{ha}^{-1} \mathrm{~N}$ at tillering favors the production of quality seeds for BRS Sabiá. The inadequate supply of $\mathrm{N}$ impairs the physiological quality of seeds produced.
\end{abstract}

Keywords: Nitrogen doses; germination; macronutrient; vigor; Triticum aestivum L. 


\section{Introdução}

O trigo, pertencente à família Poaceae, apresenta múltiplos propósitos e ocupa $\mathrm{O}$ segundo lugar em termos de consumo e produção mundial (USDA, 2019). Na safra brasileira de 2019, a área cultivada, o rendimento e a produção do cereal foram de 2,04 milhões de hectares, $2.526 \mathrm{~kg} \mathrm{ha}^{-1}$ e 5,15 milhões de toneladas (CONAB, 2020). A demanda interna por grãos de trigo ainda não é suprida pela produção nacional, sendo necessário recorrer à importação para atender a expectativa do mercado (MARINHO et al., 2018; CONAB, 2020). Dessa maneira, fica evidente a necessidade de adoção de técnicas de manejo que possam elevar a produtividade da cultura, a fim de atender a demanda interna pelo grão (COMPONOGARA et al., 2015).

Neste contexto, a produção e a utilização de sementes de qualidade é essencial, pois é determinante para a garantia de elevado desempenho agronômico e, consequentemente, para o sucesso da lavoura (FRANÇA NETO et al., 2010). A produção de sementes de qualidade é influenciada por diversos fatores, como as condições meteorológicas, a cultivar e o manejo adotado na condução da lavoura (KOLCHINSKI; $\mathrm{SCHUCH}, 2003$ ).

Entre as técnicas de manejo utilizadas no cultivo do trigo, a adubação nitrogenada destacase em razão do $\mathrm{N}$ ser o nutriente mais absorvido pelas plantas (TEIXEIRA FILHO et al., 2007; PIETRO-SOUZA et al., 2013), com respostas positivas na produtividade e qualidade dos grãos/sementes. A eficiência na utilização do $\mathrm{N}$ pela planta é influenciada pelo genótipo, que pode diferir na capacidade de emissão de perfilhos, ciclo e potencial produtivo (MARTINI JUNIOR et al., 2011). Estas diferenças podem resultar em respostas distintas à época de aplicação e à dose de $\mathrm{N}$ utilizada.
De acordo com Kolchinski e Schuch (2004), a qualidade das sementes pode ser afetada pela disponibilidade de $\mathrm{N}$ no vegetal, pois este nutriente é constituinte de inúmeras biomoléculas e é responsável por uma série de funções metabólicas essenciais para a planta. Segundo Carvalho e Nakagawa (2012), a disponibilidade de $\mathrm{N}$ afeta a composição química da semente, a formação do embrião e as estruturas de reserva e, consequentemente, o desempenho fisiológico da semente. Contudo, os seus efeitos variam de acordo com o genótipo, condições ambientais, bem como com o estádio de desenvolvimento da planta em que ocorre a aplicação do fertilizante.

Estudos que objetivam avaliar a qualidade fisiológica de sementes de diferentes genótipos de trigo associados a fertilização e nutrição de plantas são em número reduzido e os resultados nem sempre são concordantes. Neste sentido, objetivou-se avaliar o efeito do parcelamento e doses da adubação nitrogenada sobre a produtividade e a qualidade fisiológica de sementes de cultivares de trigo.

\section{Material e Métodos}

$O$ experimento foi conduzido em Londrina-PR, na estação experimental do Centro Nacional de Pesquisa de Soja (Embrapa Soja), em Latossolo Vermelho distroférrico (BHERING; SANTOS, 2008), localizado a 23ㅇ 12' $08^{\prime \prime} \mathrm{S}$ e 51응 $10^{\prime} 36^{\prime \prime} \mathrm{O}$, com altitude de $570 \mathrm{~m}$. O clima da região, segundo a classificação de Köppen, é do tipo $\mathrm{Cfa}$, descrito como subtropical úmido com verões quentes, apresentando geadas pouco frequentes e tendência de concentração das chuvas nos meses de verão, contudo sem estação seca definida. Os dados de temperatura média diária e precipitação pluviométrica durante o período de cultivo, são apresentados na Figura 1. 
Figura 1. Dados diários de temperatura média $\left({ }^{\circ} \mathrm{C}\right)$ e precipitação pluvial $(\mathrm{mm})$ durante o período de produção de sementes em campo. Londrina, PR

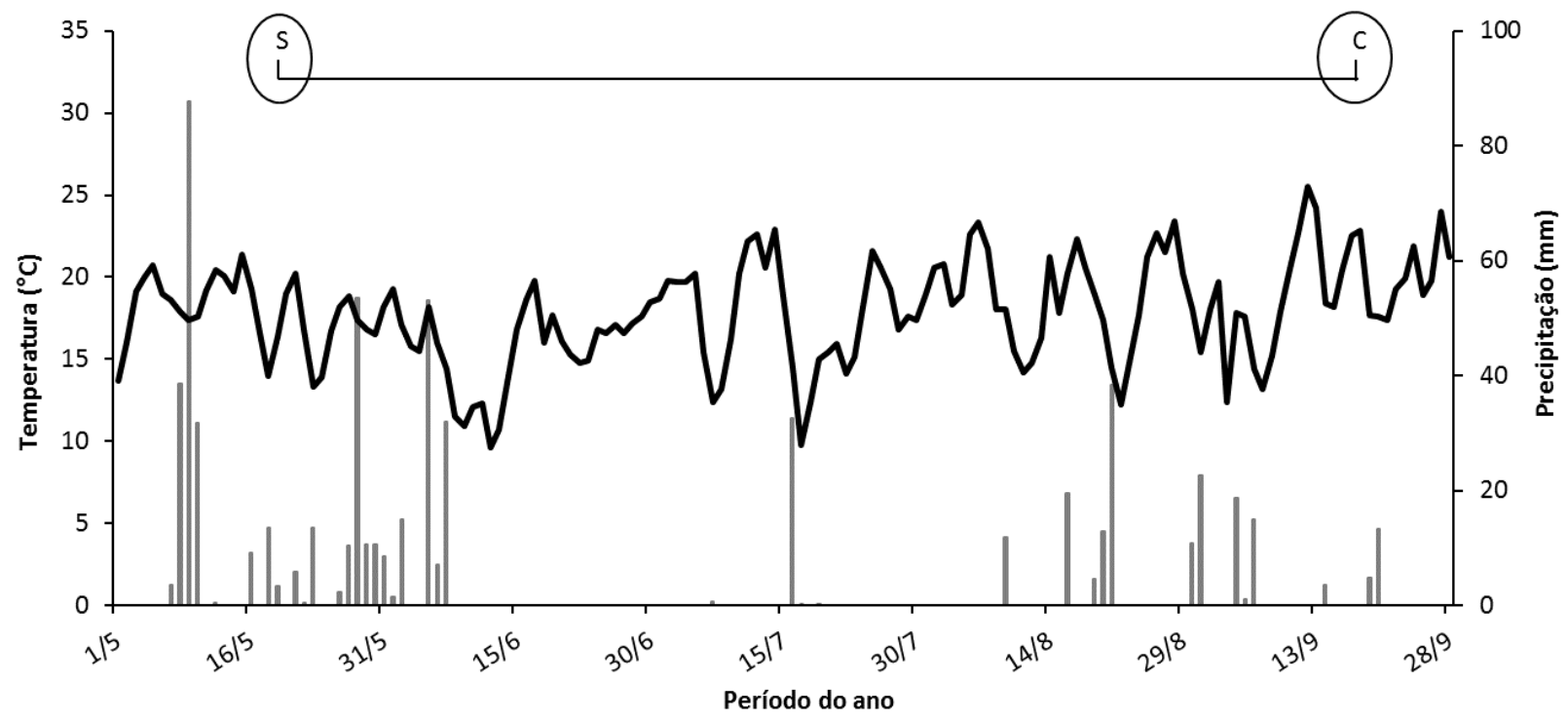

S: semeadura; C: colheita.

As características químicas do solo nas profundidades de $0-20 \mathrm{~cm}$, determinadas antes da instalação do experimento, foram representadas por: $\mathrm{pH}\left(\mathrm{H}_{2} \mathrm{O}\right)$ : 5,3; $\mathrm{P}$ (Mehlich-1): $31,7 \mathrm{mg} \mathrm{dm}^{-3} ; \mathrm{H}+\mathrm{Al}: 3,46 \mathrm{cmol}_{\mathrm{c}} \mathrm{dm}^{-3} ; \mathrm{K}: 0,95$ $\mathrm{cmol}_{\mathrm{c}} \mathrm{dm}^{-3} ;$ Ca: $4,8 \mathrm{cmol}_{\mathrm{c}} \mathrm{dm}^{-3} ; \mathrm{Mg}: 1,87 \mathrm{cmol}_{\mathrm{c}}$ $\mathrm{dm}^{-3}$; CTC: $10,36 \mathrm{cmol}_{\mathrm{c}} \mathrm{dm}^{-3}$; saturação por bases (V): $66 \%$.

O experimento foi conduzido em área de sistema de plantio direto utilizando-se as cultivares BRS Gralha-azul (ciclo médio; moderadamente suscetível ao acamamento; estatura média, em torno de $83 \mathrm{~cm}$ ) e BRS Sabiá (ciclo precoce; moderadamente resistente ao acamamento; estatura média, em torno de 88 $\mathrm{cm})$. O delineamento experimental utilizado foi o de blocos casualizados em esquema fatorial $2 \times 7$, com quatro repetições. Os tratamentos consistiram em duas cultivares de trigo (BRS Gralha-azul e BRS Sabiá) e sete combinações de aplicação da adução nitrogenada (Tabela 1).

Tabela 1. Combinações de épocas e doses da adubação nitrogenada aplicadas nas cultivares de trigo BRS Gralha-azul e BRS Sabiá

\section{Épocas de aplicação}

Doses

Semeadura (kg ha $\left.{ }^{-1}\right)$

Início do Perfilhamento (kg ha ${ }^{-1}$ )

\begin{tabular}{ccc}
\hline $\mathbf{0 N}$ & $0 \mathrm{~N}$ & $0 \mathrm{~N}$ \\
$\mathbf{0 N + 4 0 N}$ & $0 \mathrm{~N}$ & $40 \mathrm{~N}$ \\
$\mathbf{0 N + 8 0 N}$ & $0 \mathrm{~N}$ & $80 \mathrm{~N}$ \\
$\mathbf{4 0 N + 0 N}$ & $40 \mathrm{~N}$ & $0 \mathrm{~N}$ \\
$\mathbf{8 0 N + 0 N}$ & $80 \mathrm{~N}$ & $0 \mathrm{~N}$ \\
$\mathbf{4 0 N + 4 0 N}$ & $40 \mathrm{~N}$ & $40 \mathrm{~N}$ \\
$\mathbf{2 0 N + 6 0 N}$ & $20 \mathrm{~N}$ & $60 \mathrm{~N}$ \\
\hline
\end{tabular}

Na semeadura, realizada em 18 de maio, foi feita a adubação com $250 \mathrm{~kg} \mathrm{ha}{ }^{-1}$ do fertilizante formulado 00-20-20 (NPK). A primeira parcela da adubação nitrogenada de cobertura foi realizada a lanço no dia da semeadura, e a segunda parcela foi realizada, da mesma forma, no início da fase de perfilhamento (estádio fenológico 2, escala de Feekes), utilizando o nitrato de amônio como fonte de $\mathrm{N}$ (32\% de N). 
As parcelas foram compostas por dez linhas de seis metros de comprimento, espaçadas em 0,2 m, considerando-se como área útil as seis linhas centrais, desprezando-se um metro de cada extremidade. A área útil da unidade experimental foi de $4,8 \mathrm{~m}^{2}$.

Os tratos culturais foram conduzidos seguindo as recomendações de manejo da Comissão Brasileira de Pesquisa de Trigo e Triticale (2018). A colheita foi realizada em 18 de setembro, após as sementes atingirem a maturação de colheita, caracterizado pelo endurecimento da cariopse, plantas com aspecto seco e sementes com umidade abaixo de $20 \%$. Para a determinação da produtividade e da qualidade fisiológica das sementes foram realizadas as seguintes avaliações:

Produtividade: determinada pela colheita das plantas contidas na área útil das unidades experimentais. Após a trilhagem mecânica, o grau de umidade das sementes foi mensurado por um determinador de capacitância digital, modelo GAC 2100, previamente ajustado e calibrado para a cultura do trigo. Posteriormente, as sementes foram pesadas e os dados, corrigidos para $13 \%$ de umidade, foram expressos em $\mathrm{kg} \mathrm{ha}^{-1}$.

Germinação: realizada com oito repetições de 50 sementes por tratamento, em papel toalha tipo Germitest ${ }^{\circledast}$ umedecido com água destilada, na proporção de 2,5 vezes a massa do substrato seco. Os rolos de papel foram mantidos em germinador tipo Mangelsdorf sob temperatura constante de $20{ }^{\circ} \mathrm{C}$. Aos quatro (primeira contagem) e aos oito dias (germinação) após a instalação do teste realizou-se as avaliações, registrando-se o número de plântulas normais, sendo os resultados expressos em porcentagem (BRASIL, 2009).

Comprimento de plântulas: realizado a partir da semeadura de quatro repetições de 20 sementes, por tratamento, no terço superior do papel de germinação, umedecido com água destilada na proporção de 2,5 vezes a massa do substrato seco. Os rolos de papel foram acondicionados em germinador por cinco dias a $20{ }^{\circ} \mathrm{C}$, no escuro (ABATI et al., 2014). Ao final deste período, foi efetuada a medida das plântulas normais com auxílio de uma régua graduada. Os resultados foram expressos em centímetros por plântula.

Massa seca de plântulas: as plântulas normais obtidas no teste de comprimento foram acondicionadas em sacos de papel e levadas à estufa com circulação de ar forçada à $80^{\circ} \mathrm{C} \pm 5^{\circ} \mathrm{C}$ até atingirem massa constante (NAKAGAWA, 1999). Posteriormente, cada repetição teve a massa avaliada em balança com precisão de $0,001 \mathrm{~g}$, e os resultados médios expressos em miligramas por plântula.

Emergência de plântulas em areia: realizado em casa de vegetação utilizando quatro repetições de 50 sementes, que foram semeadas, em caixas de areia, a $4 \mathrm{~cm}$ de profundidade. A umidade foi mantida com irrigações de acordo com a necessidade. Após 15 dias da semeadura foi contabilizado o número de plântulas normais emersas, sendo os resultados expressos em porcentagem.

Índice de velocidade de emergência: conduzido em conjunto com o teste de emergência de plântulas em areia, sendo as contagens de plântulas emergidas realizadas diariamente, até a estabilização da emergência. Através dos resultados foram calculados os índices de velocidade de emergência (MAGUIRE, 1962).

Os dados foram submetidos às análises de normalidade e homogeneidade dos erros e, posteriormente, a análise de variância. As médias das cultivares foram comparadas pelo teste $\mathrm{F}$ e dos tratamentos com a adubação nitrogenada pelo teste de Scott-Knott, a 5\% de probabilidade.

\section{Resultados e Discussão}

Verificou-se efeito de interação entre os fatores cultivar e adubação nitrogenada para as variáveis produtividade, primeira contagem, comprimento de plântulas e massa seca de plântulas. Para a germinação, observou-se efeito isolado da adubação com $\mathrm{N}$. As demais variáveis não foram influenciadas significativamente de forma isolada ou pela interação entre os fatores (Tabela 2). 
Tabela 2. Valores do quadrado médio da análise de variância da produtividade (Prod), primeira contagem $(P C)$, germinação $(G)$, comprimento de plântulas (CP), massa seca de plântulas (MSP), emergência de plântulas em areia (EP) e índice de velocidade de emergência (IVE) das sementes de trigo, em função da cultivar e da aplicação de diferentes combinações de nitrogênio

\begin{tabular}{cccccccc}
\hline \multirow{2}{*}{ Fonte de variação } & \multicolumn{7}{c}{ Características } \\
\cline { 2 - 8 } & Prod $\left(\mathbf{k g ~ h a}^{-1}\right)$ & $\mathbf{P C}(\%)$ & $\mathbf{G}(\%)$ & $\mathbf{C P}(\mathbf{c m})$ & $\mathbf{M S P}(\mathbf{m g})$ & EP (\%) & IVE \\
\hline Bloco & 38345 & 34,45 & 17,79 & 0,06 & 0,31 & 14,17 & 0,03 \\
Cultivar (C) & $474249^{*}$ & $66,45^{*}$ & $0,29^{\text {ns }}$ & $0,12^{\text {ns }}$ & $1,04^{\text {ns }}$ & $68,64^{\text {ns }}$ & $3,68^{\text {ns }}$ \\
Aplicação de N (N) & $301177^{*}$ & $134,64^{*}$ & $49,16^{*}$ & $14,18^{*}$ & $3,72^{*}$ & $38,62^{\text {ns }}$ & $0,32^{\text {ns }}$ \\
C x N & $70155^{*}$ & $86,57^{*}$ & $4,24^{\text {ns }}$ & $23,79^{*}$ & $3,88^{*}$ & $27,81^{\text {ns }}$ & $0,85^{\text {ns }}$ \\
\hline CV (\%) & 3,64 & 4,38 & 3,25 & 4,70 & 9,37 & 6,61 & 10,58 \\
\hline${ }^{\text {ns }}$ : não significativo; * significativo à 5\% de probabilidade pelo teste F, CV: coeficiente de variação.
\end{tabular}

Para a produtividade, constatou-se diferença significativa entre as cultivares para os tratamentos $0 \mathrm{~N}, 40 \mathrm{~N}+40 \mathrm{~N}$ e $20 \mathrm{~N}+60 \mathrm{~N}$, sendo os maiores valores encontrados para a BRS Gralhaazul em comparação com a BRS Sabiá. As demais combinações de aplicação de $\mathrm{N}$ não apresentaram diferença significativa entre as cultivares. Para a BRS Gralha-azul, as maiores produtividades foram encontradas para os tratamentos $0 \mathrm{~N}, 40 \mathrm{~N}+0 \mathrm{~N}$ e $20 \mathrm{~N}+60 \mathrm{~N}$. Já para a BRS Sabiá, a maior produtividade foi observada para o tratamento $40 \mathrm{~N}+0 \mathrm{~N}$, sendo os demais agrupados como de valores medianos, com exceção do tratamento $40 \mathrm{~N}+40 \mathrm{~N}$, que apresentou a menor produtividade para esta cultivar (Tabela 3).

Tabela 3. Valores médios de produtividade e da primeira contagem da germinação de sementes das cultivares de trigo BRS Gralha-azul e BRS Sabiá, em função da adubação nitrogenada

\begin{tabular}{|c|c|c|c|c|}
\hline \multirow{3}{*}{$\mathbf{N}$} & \multicolumn{4}{|c|}{ Cultivares } \\
\hline & \multicolumn{2}{|c|}{ Produtividade $\left(\mathrm{kg} \mathrm{ha}^{-1}\right)$} & \multicolumn{2}{|c|}{ Primeira contagem (\%) } \\
\hline & BRS Gralha-azul & BRS Sabiá & BRS Gralha-azul & BRS Sabiá \\
\hline ON & $3739.66 \mathrm{aA}$ & $3325.31 \mathrm{bB}$ & $88 \mathrm{aB}$ & $86 \mathrm{aB}$ \\
\hline $0 N+40 N$ & $3295.00 \mathrm{aB}$ & $3318.66 \mathrm{aB}$ & $84 \mathrm{bB}$ & $92 \mathrm{aA}$ \\
\hline $0 N+80 N$ & $3294.64 \mathrm{aB}$ & $3283.98 \mathrm{aB}$ & $93 \mathrm{aA}$ & $94 \mathrm{aA}$ \\
\hline $40 N+0 N$ & $3707.42 \mathrm{aA}$ & $3534.60 \mathrm{aA}$ & $93 \mathrm{aA}$ & $93 \mathrm{aA}$ \\
\hline $80 N+0 N$ & $3353.03 \mathrm{aB}$ & $3323.54 \mathrm{aB}$ & $92 \mathrm{aA}$ & $85 \mathrm{bB}$ \\
\hline $40 N+40 N$ & $3243.46 \mathrm{aB}$ & $2830.07 \mathrm{bC}$ & $88 \mathrm{aB}$ & $75 \mathrm{bC}$ \\
\hline $20 N+60 N$ & $3623.97 \mathrm{aA}$ & $3352.66 \mathrm{bB}$ & $87 \mathrm{aB}$ & $87 \mathrm{aB}$ \\
\hline
\end{tabular}

Médias seguidas da mesma letra minúscula na linha e maiúscula na coluna, não diferem entre si pelo teste $\mathrm{F}$ e pelo teste de Scott-Knott, respectivamente $(\mathrm{P}<0,05)$.

Para a primeira contagem, observou-se diferença significativa entre as cultivares para o tratamento $0 \mathrm{~N}+40 \mathrm{~N}$, com o maior valor desta variável encontrado para BRS Sabiá. Já para os tratamentos $80 \mathrm{~N}+0 \mathrm{~N}$ e $40 \mathrm{~N}+40 \mathrm{~N}$, os maiores valores foram verificados para BRS Gralha-azul. As demais combinações de aplicação de $\mathrm{N}$ não apresentaram diferença significativa entre as cultivares. Para a BRS Gralha-azul, os tratamentos $0 \mathrm{~N}+80 \mathrm{~N}, 40 \mathrm{~N}+0 \mathrm{~N}$ e $80 \mathrm{~N}+0 \mathrm{~N}$ apresentaram as maiores porcentagens de plântulas normais na primeira contagem. Para a BRS Sabiá, os tratamentos $0 \mathrm{~N}+40 \mathrm{~N}, 0 \mathrm{~N}+80 \mathrm{~N}$ e $40 \mathrm{~N}+0 \mathrm{~N}$ tiveram o melhor desempenho, já o tratamento $40 \mathrm{~N}+40 \mathrm{~N}$ apresentou o menor valor observado (Tabela 3 ).

Os maiores valores de germinação de sementes, independentemente da cultivar analisada, foram observados para os tratamentos $0 \mathrm{~N}+80 \mathrm{~N}, \quad 40 \mathrm{~N}+0 \mathrm{~N}$ e $80 \mathrm{~N}+0 \mathrm{~N}$, já os demais tratamentos apresentaram valores inferiores. Destaca-se que as doses $80 \mathrm{~kg} \mathrm{ha}^{-1} \mathrm{~N}$, aplicadas tanto na semeadura como em cobertura, e a 
dose de $40 \mathrm{~kg} \mathrm{ha}^{-1} \mathrm{~N}$ na semeadura, favoreceram o número de plântulas normais no teste de germinação (Tabela 4).

Tabela 4. Valores médios de germinação em função da adubação nitrogenada

\begin{tabular}{cc}
\hline \multirow{N}{*}{$\mathbf{N}$} & Característica \\
\cline { 2 - 2 } 0N & Germinação (\%) \\
$\mathbf{0 N + 4 0 N}$ & $88 \mathrm{~B}$ \\
$\mathbf{0 N + 8 0 N}$ & $92 \mathrm{~B}$ \\
$\mathbf{4 0 N + 0 N}$ & $95 \mathrm{~A}$ \\
$\mathbf{8 0 N + 0 N}$ & $95 \mathrm{~A}$ \\
$\mathbf{4 0 N + 4 0 N}$ & $93 \mathrm{~A}$ \\
$\mathbf{2 0 N + 6 0 N}$ & $91 \mathrm{~B}$ \\
\hline
\end{tabular}

Médias seguidas de mesma letra não diferem entre si pelo teste de Scott-Knott $(P<0,05)$.
A cultivar BRS Gralha-azul apresentou maior comprimento de plântulas nos tratamentos ON+40N e $80 N+0 N$, em comparação a BRS Sabiá. Para os demais tratamentos com N, a BRS Sabiá obteve os melhores valores para este caractere. Os melhores resultados de comprimento de plântulas para a BRS Gralha-azul também foram encontrados nos tratamentos $0 \mathrm{~N}+40 \mathrm{~N}$ e $80 \mathrm{~N}+0 \mathrm{~N}$. Para a BRS Sabiá, os tratamentos $0 \mathrm{~N}+80 \mathrm{~N}$, $40 N+0 N$ e $20 N+60 N$ resultaram no desenvolvimento de plântulas de maior comprimento, já o tratamento $0 \mathrm{~N}+40 \mathrm{~N}$ foi o que apresentou o menor valor para esta característica (Tabela 5).

Tabela 5. Valores médios de comprimento e massa seca de plântulas das cultivares de trigo BRS Gralha-azul e BRS Sabia, em função da adubação nitrogenada

\begin{tabular}{|c|c|c|c|c|}
\hline \multirow{3}{*}{$\mathbf{N}$} & \multicolumn{4}{|c|}{ Cultivares } \\
\hline & \multicolumn{2}{|c|}{ Comprimento de plântulas $(\mathrm{cm})$} & \multicolumn{2}{|c|}{ Massa seca de plântulas (mg) } \\
\hline & BRS Gralha-azul & BRS Sabiá & BRS Gralha-azul & BRS Sabiá \\
\hline ON & 10,13 bD & $12,42 \mathrm{aB}$ & $4,89 \mathrm{bB}$ & $6,21 \mathrm{aB}$ \\
\hline $0 N+40 N$ & $15,22 \mathrm{aA}$ & $9,78 \mathrm{bD}$ & 7,04 aA & $5,11 \mathrm{bC}$ \\
\hline $0 N+80 N$ & $11,64 \mathrm{bc}$ & 14,69 aA & $4,95 \mathrm{bB}$ & $7,04 \mathrm{aA}$ \\
\hline $40 N+0 N$ & $13,11 \mathrm{bB}$ & $15,60 \mathrm{aA}$ & 6,70 aA & $7,39 \mathrm{aA}$ \\
\hline $80 N+0 N$ & $15,12 \mathrm{aA}$ & $10,89 \mathrm{bC}$ & $6,22 \mathrm{aA}$ & $5,05 \mathrm{bC}$ \\
\hline $40 N+40 N$ & $10,47 \mathrm{bD}$ & $11,57 \mathrm{aB}$ & $5,63 \mathrm{aB}$ & $6,20 \mathrm{aB}$ \\
\hline $20 N+60 N$ & $13,67 \mathrm{bB}$ & 15,07 aA & $7,12 \mathrm{aA}$ & $7,47 \mathrm{aA}$ \\
\hline
\end{tabular}

Médias seguidas da mesma letra minúscula na linha e maiúscula na coluna, não diferem entre si pelo teste $\mathrm{F}$ e pelo teste de Scott-Knott, respectivamente $(P<0,05)$.

Para a massa seca de plântulas, entre as cultivares, os tratamentos $0 \mathrm{~N}+40 \mathrm{~N}$ e $80 \mathrm{~N}+0 \mathrm{~N}$ resultaram em maiores valores para a BRS Gralha-azul, já os tratamentos $0 \mathrm{~N}$ e $\mathrm{ON}+80 \mathrm{~N}$ favoreceram a BRS Sabiá. As demais combinações de aplicação de $\mathrm{N}$ não apresentaram diferença significativa entre as cultivares. Para a BRS Gralha-azul os melhores resultados foram obtidos nos tratamentos $0 \mathrm{~N}+40 \mathrm{~N}, 40 \mathrm{~N}+0 \mathrm{~N}, 80 \mathrm{~N}+0 \mathrm{~N}$ e $20 \mathrm{~N}+60 \mathrm{~N}$, já para a BRS Sabiá os maiores valores para esta característica foram encontrados em 0N+80N, 40N+0N e 20N+60N (Tabela 5).

Para a cultivar BRS Gralha-azul, verificouse que o potencial produtivo máximo foi atingido (nas condições em que o experimento foi conduzido) mesmo com a ausência da adubação nitrogenada, uma vez que o tratamento ON proporcionou elevado rendimento de sementes, juntamente com os tratamentos $40 \mathrm{~N}+0 \mathrm{~N}$ e $20 N+60 N$. Isso reflete a elevada capacidade de compensação entre os componentes de produção dessa cultivar, que interagem entre si para manter elevado o rendimento de sementes, mesmo sem o N. A adubação nitrogenada foi essencial para a produção de sementes de qualidade, pois o tratamento sem aplicação de $\mathrm{N}$ (ON) resultou em reduzidos valores para as características relacionadas ao potencial fisiológico de sementes. A falta deste nutriente pode ter prejudicado a formação do tecido de reserva das sementes, o que possivelmente 
reduziu o desempenho fisiológico das mesmas (KOLCHINSKI; SCHUCH, 2003).

A qualidade fisiológica das sementes produzidas pela cultivar BRS Gralha-azul foi favorecida pelo tratamento $80 \mathrm{~N}+0 \mathrm{~N}$ e, além disso, proporcionou melhor desempenho dessa cultivar em comparação a BRS Sabiá.

Para a BRS Sabiá, a adubação nitrogenada influenciou positivamente todas as características avaliadas, sendo os tratamentos $0 \mathrm{~N}+80 \mathrm{~N}$ e $40 N+0 N$ os que proporcionaram melhor desempenho das sementes, principalmente nas variáveis comprimento e massa seca de plântulas, em que foi observada a superioridade deste genótipo, em comparação a BRS Gralha-azul, nos tratamentos citados.

A resposta do trigo à adubação nitrogenada varia em virtude do genótipo (BAZZO et al., 2019) e das condições de cultivo (SANGOI et al., 2007). Costa et al. (2013), também constataram respostas diferentes à adubação nitrogenada parcelada de diversas formas, em virtude do genótipo.

De forma geral, o $\mathrm{N}$ afetou positivamente a qualidade fisiológica das sementes de ambas as cultivares, o que evidencia a importância deste nutriente para a formação de sementes de qualidade superior. Estudos indicam que $\mathrm{O}$ conteúdo de $\mathrm{N}$, absorvido pela planta durante seu ciclo, tem correlação positiva com o teor de proteína e a qualidade fisiológica das sementes produzidas (CARVALHO; NAKAGAWA, 2012).

Segundo Sá (1994), a disponibilidade de nutrientes essenciais, como $0 \mathrm{~N}$, interfere diretamente na qualidade das sementes produzidas, pois afeta a composição química, a formação do embrião e dos tecidos de reserva, o que tem influência direta no potencial fisiológico das mesmas, além de que, plantas bem nutridas produzem sementes de melhor qualidade.

Espindula et al. (2010), estudando a composição mineral de trigo submetido a doses de sulfato de amônio, observaram que a adubação nitrogenada elevou a qualidade deste cereal pelo incremento da concentração de proteínas e de outros nutrientes. Altenbach et al. (2011) também verificaram aumento no teor de proteínas do trigo decorrente da adubação nitrogenada.

É importante ressaltar que o tratamento $40 \mathrm{~N}+40 \mathrm{~N}$, para ambas as cultivares, resultou no baixo desempenho das sementes. Isso, aliado ao fato dos melhores tratamentos incluírem apenas uma única dose de $\mathrm{N}$ evidencia que, para a $\mathrm{BRS}$
Gralha-azul e a BRS Sabiá, a aplicação única de N (na semeadura ou no início do perfilhamento), proporciona melhor qualidade de sementes e melhor produtividade (para BRS Sabiá). Estes resultados corroboram Costa et al. (2013), que verificaram que os genótipos IPR 136 e LD 052114 tiveram melhor desempenho quando o $\mathrm{N}$, na dose de $80 \mathrm{~kg} \mathrm{ha}^{-1}$, foi aplicado uma única vez no perfilhamento e no emborrachamento, respectivamente.

A aplicação de uma única dose de $\mathrm{N}$ durante o ciclo do trigo contribui com a redução dos custos de produção, contudo este tipo de manejo depende das condições climáticas, principalmente da precipitação pluvial. $O$ excesso ou a escassez de chuva antes ou depois da aplicação da adubação nitrogenada pode comprometer a disponibilidade de $\mathrm{N}$ para a cultura por acarretar perdas por lixiviação, na forma de nitrato, ou por volatilização, na forma de amônia, respectivamente (TASCA et al., 2011).

$$
\text { As condições meteorológicas }
$$

(temperatura e precipitação) durante a produção das sementes (Figura 1) e as cultivares utilizadas foram favoráveis à aplicação de uma única dose de $\mathrm{N}$ (80 kg ha ${ }^{-1} \mathrm{~N}$ e $40 \mathrm{~kg} \mathrm{ha}^{-1} \mathrm{~N}$ ), em uma única época (semeadura ou início do perfilhamento), que diferiu entre os genótipos, mas que resultou na produção de sementes vigorosas.

Segundo Sangoi et al. (2007), diferentes genótipos de trigo diferem na sua capacidade de emissão de perfilhos, no seu ciclo, na arquitetura e no potencial produtivo e estas diferenças podem interferir na capacidade de absorção, de assimilação e de conversão de $\mathrm{N}$ para a produção de sementes. Além disso, genótipos com bases genéticas diferentes também apresentam resposta diferenciada à aplicação de $\mathrm{N}$. Isso explica a diferença quanto à melhor época e dose de $\mathrm{N}$ aplicada entre os dois genótipos.

Com base no exposto, pode-se afirmar que a aplicação de $\mathrm{N}$ na dose correta e na fase de desenvolvimento adequada é essencial para aumentar a sua eficiência nas plantas, favorecer o rendimento e a qualidade das sementes e reduzir possíveis perdas de $\mathrm{N}$ por lixiviação e volatilização (BAZZO et al., 2016), principalmente em regiões tropicais e subtropicais, onde esses processos ocorrem com maior frequência e intensidade, devido as precipitações pluviais mais prolongadas e intensas. 


\section{Conclusões}

A máxima produtividade de sementes da cultivar BRS Gralha-azul é atingida mesmo na ausência da adubação nitrogenada e para a cultivar BRS Sábia é atingida com $40 \mathrm{~kg}$ de $\mathrm{N} \mathrm{ha}^{-1}$ fornecido na semeadura.

O potencial fisiológico de sementes de ambas as cultivares é elevado com adubação nitrogenada aplicada em uma única dose, tanto na semeadura quanto em cobertura.

A dose de $40 \mathrm{~kg}$ de $\mathrm{N} \mathrm{ha}^{-1}$ aplicada na semeadura é suficiente para produção de sementes com melhor germinação e vigor para ambas as cultivares.

Independentemente da cultivar avaliada, o suprimento inadequado de $\mathrm{N}$ (na dose e na época inadequadas) reduz a germinação e o vigor das sementes produzidas.

\section{Referências}

ABATI, J.; ZUCARELI, C.; FOLONI, J.S.S.; HENNING, F.A.; BRZEZINSKI, C.R.; HENNING, A.A. Treatment with fungicides and insecticides on the physiological quality and health of wheat seeds. Journal of Seed Science, v.36, n.4, p.392-398, $2014 . \quad$ https://doi.org/10.1590/2317$\underline{1545 v 36 n 41006}$

ALTENBACH, S.B.; TANAKA, C.K.; HURKMAN, W.J.; WHITEHAND, L.C.; VENSEL, W.H.; DUPONT, F.M. Differential effects of a post-anthesis fertilizer regimen on the wheat flour proteome determined by quantitative 2-DE. Proteome Science, v.9, n.46, p.1-13, 2011. http://dx.doi.org/10.1186/1477-5956-9-46.

BAZZO, J.H.B.; FRACALOSSI, F.P.; ZUCARELI, C.; FONSECA, I.C.B.; BARBOSA, A.P.; SANTOS, R.J. Wheat production performance in response to nitrogen sidedressing and molybdenum leaf application. Semina: Ciências Agrárias, v.37, n.5, p.2963-2976, 2016.

http://dx.doi.org/10.5433/16790359.2016v37n5p2963.

BAZZO, J.H.B.; RIEDE, C.R.; ARRUDA, K.M.A.; CARDOSO, C.P.; FRANZONI, I.; FONSECA, I.C.B.; ZUCARELI, C. Performance of white oat cultivars in response to nitrogen fertilization and trinexapac-ethyl. Semina: Ciências Agrárias, v.40, n.5, p.2121-2136, 2019. http://dx.doi.org/10.5433/16790359.2019v40n5Supl1p2121.
BHERING, S.B.; SANTOS, H.G. Mapa de solos do estado do Paraná: legenda atualizada. Rio de Janeiro, Embrapa Solos; Londrina: Iapar, Embrapa Florestas, 2008. $74 \mathrm{p}$.

BRASIL. Ministério da Agricultura, Pecuária e Abastecimento. Regras para análise de sementes. Brasília: Mapa/ACS, 2009. 399 p.

CARVALHO, N.M.; NAKAGAWA, J. Sementes: ciência, tecnologia e produção. 5. ed. Jaboticabal: FUNEP, 2012. $590 \mathrm{p}$.

COMISSÃO BRASILEIRA DE PESQUISA DE TRIGO E TRITICALE. Informações técnicas para trigo e triticale - safra 2019. Brasília: Embrapa, 2018. $240 \mathrm{p}$.

COMPONOGARA, A.; GALLIO, E.; BORBA, W.F.; GEORGIN, J. O atual contexto da produção de trigo no Rio Grande do Sul. Revista Eletrônica em Gestão, Educação e Tecnologia Ambiental, v.19, n.2, p.246-257, 2015. http://dx.doi.org/10.5902/2236117015437

CONAB. Acompanhamento da safra brasileira de grãos - Safra 2019/20 - Quarto levantamento. Brasília: Ministério da Agricultura, Pecuária e Abastecimento, 2020. 104 p.

COSTA, L.; ZUCARELI, C.; RIEDE, C.R. Parcelamento da adubação nitrogenada no desempenho produtivo de genótipos de trigo. Revista Ciência Agronômica, v.44, n.2, p.215-224, $2013 . \quad$ https://doi.org/10.1590/S1806$\underline{66902013000200002}$

ESPINDULA, M.C.; ROCHA, V.S.; SOUZA, M.A.; GROSSI, J.A.S.; SOUZA, L.T. Doses e formas de aplicação de nitrogênio no desenvolvimento e produção da cultura do trigo. Ciência e Agrotecnologia, v.34, n.6, p.1404-1411, 2010. https://doi.org/10.1590/S141370542010000600007

FRANÇA NETO, J.B.; KRZYZANOWSKI, F.C.; HENNING, A.A. A importância do uso de semente de soja de alta qualidade. Informativo ABRATES, v.20, n.1,2, p.037-038, 2010.

KOLCHINSKI, E.M.; SCHUCH, L.O.B. Eficiência no uso do nitrogênio por cultivares de aveia branca de acordo com a adubação nitrogenada. Revista Brasileira de Ciência do Solo, v.27, n.6, p.1033- 
1038, 2003. https://doi.org/10.1590/S010006832003000600007

KOLCHINSKI, E.M; SCHUCH, L.O.B. Relações entre a adubação nitrogenada e a qualidade de grãos e de sementes em aveia branca. Ciência Rural, v.34, n.2, p.379-383, 2004. https://doi.org/10.1590/S0103$\underline{84782004000200007}$

MAGUIRE, J.D. Speed of germination-aid in selection and evaluation for seedling emergence and vigor. Crop Science, v.2, n.2, p.176-177, 1962.

http://dx.doi.org/10.2135/cropsci1962.0011183X $\underline{000200020033 x}$

MARINHO, J.L.; BAZZO, J.H.B.; CARDOSO, C.P.; ZUCARELI, C.; FONSECA, I.C.B.F. Produtividade e qualidade fisiológica de sementes de cultivares de trigo em diferentes densidades de semeadura. Colloquium Agrariae, v.14, n.3, p.122-131, 2018. http://dx.doi.org/10.5747/ca.2018.v14.n3.a234

MARTINI JUNIOR, P.C.; FERREIRA, D.T.L.; MOREIRA, G.C. Características agronômicas da cultivar de trigo CD 114 submetido à aplicação nitrogenada em cobertura. Cultivando o Saber, v.4, n.3, p.158-172, 2011.

NAKAGAWA, J. Testes de vigor baseados no desempenho das plântulas. In: KRYZANOWSKI, F.C.; VIEIRA, R.D.; FRANÇA-NETO, J.B. (Ed.). Vigor de sementes: conceitos e testes. Londrina: ABRATES, 1999. p.2.1-2.24.

PIETRO-SOUZA, W.; BONFIM-SILVA, E.M.; SCHLICHTING, A.F.; SILVA, M.C. Desenvolvimento inicial de trigo sob doses de nitrogênio em Latossolo Vermelho de Cerrado. Revista Brasileira de Engenharia Agrícola e Ambiental, v.17, n.6, p.575-580, 2013. https://doi.org/10.1590/S141543662013000600001

SÁ, M.E. Importância da adubação nitrogenada na qualidade de sementes. In: SÁ, M.E.; BUZZETTI, S. (Coord.) Importância da adubação na qualidade dos produtos agrícolas. São Paulo: Ícone, 1994. p. 65-98.

SANGOI, L.; BERNS, A.C.; ALMEIDA, M.L.; ZANIN, C.G.; SCHWEITZER, C. Características agronômicas de cultivares de trigo em resposta à época da adubação nitrogenada de cobertura. Ciência Rural, v.37, n.6, p.1564-1570, 2007. https://doi.org/10.1590/S0103$\underline{84782007000600010}$

TASCA, F.A.; ERNANI, P.R.; ROGERI, D.A.; GATIBONI, L.C.; CASSOL, P.C. Volatilização de amônia do solo após a aplicação de ureia convencional ou com inibidor de uréase. Revista Brasileira de Ciência do Solo, v.35, n.2, p.493502, 2011. https://doi.org/10.1590/S0100$\underline{06832011000200018}$

TEIXEIRA FILHO, M.C.M.; BUZETTI, S.; ALVAREZ, R.C.F.; FREITAS, J.G.; ARF, O.; SÁ, M.E. Resposta de cultivares de trigo irrigados por aspersão ao nitrogênio em cobertura na região do Cerrado. Acta Scientiarum Agronomy, v.29, n.3, p.421425, 2007.

https://doi.org/10.4025/actasciagron.v29i3.471

USDA. U.S. All-Wheat 2019/20 production and carryout forecast to exceed 2018/19 estimates. $2019 . \quad$ Disponível em: https://www.ers.usda.gov/webdocs/publications /93090/whs-19e.pdf?v=4401.4 